\title{
Ouvir o Espírito \\ Caminho da mística cristã e de uma espiritualidade humanizadora
}

\author{
Learning the Holy Spirit \\ The way for a Christian mystique and for a humanizing spirituality
}

Marcio Simão de Vasconcellos

\section{Resumo}

Esta comunicação busca refletir sobre a experiência mística cristã tendo como critério a proposta de Yves Congar de uma pneumatologia cristológica e uma cristologia pneumatológica. A partir dessa reflexão, o texto deseja apresentar alguns critérios de discernimento que auxiliem no processo de identificar quais elementos devem estar presentes num projeto de espiritualidade genuinamente cristã. Como critério máximo para essa proposta, investigaremos a vida e ministério de Jesus buscando perceber como a experiência de Deus o conduzia em seus relacionamentos com a vida e com o próximo. Em outras palavras, a partir da espiritualidade de Jesus, plena do Espírito de Deus, encontraremos propostas para nossa própria espiritualidade. Nesse sentido, ouvir a voz do Espírito significa abrir-se ao seu vento renovador e, por vezes, imprevisível, mas que sempre nos aproxima do Cristo de Deus. Este caminho revela-se como a única maneira de vincular mística cristã e uma espiritualidade humanizadora no seguimento de Jesus.

Palavras-chave: pneumatologia, mística cristã, espiritualidade.

\section{Abstract}

This communication intends to reflect about the Christian mystical experience having as criterion the proposal of Yves Congar of a christological 
pneumatology and Christology pneumatologic. Based on this discussion, the text you wish to present some criteria of discernment to help in the process of identifying which elements should be present in a project of genuine Christian spirituality. As maximum criterion for this proposal, we will investigate the life and ministry of Jesus seeking to understand how the experience of God led him in their relationships with life and the next. In other words, from the spirituality of Jesus, full of the Spirit of God, we find proposals for our own spirituality. In this sense, hear the voice of Spirit means opening up to its renovator wind and sometimes unpredictable, but always close to the Christ of God. This path reveals itself as the only way to link Christian mystical and spirituality humanizing in following Jesus

Keywords: pneumatology, Christian mystical, spirituality.

\section{Introdução}

Há uma frase, repetida no livro do Apocalipse, que retrata uma necessidade e uma responsabilidade da igreja em nossos dias: "Quem tem ouvidos, ouça o que o Espírito diz às igrejas". Essas palavras, presentes no final de cada uma das cartas do livro do Apocalipse, nos convidam, enquanto seguidores e seguidoras de Jesus, à experiência com o Espírito do Cristo ressurreto que as proclama.

Mas não se trata apenas de um convite para ouvir, mas também para encarnar a mensagem do Espírito na vida, no cotidiano. Nesse sentido, são palavras que exigem uma cuidadosa reflexão. Por isso, trazer à memória o que 0 Espírito de Jesus nos fala, especialmente em tempos confusos como os nossos, torna-se, não só fundamentalmente importante, como também a única maneira de guardar a fidelidade à mensagem de Jesus. De fato, ouvir a voz do Espírito de Deus é o maior desafio e, ao mesmo tempo, a maior necessidade dos cristãos em nosso tempo. Num momento de redescoberta da dimensão pneumatológica da vida pela igreja cristã ${ }^{1}$, refletir sobre o Espírito Santo é uma tarefa abrangente, capaz de gerar renovação especialmente no que se relaciona ao modelo de seguimento de Jesus que adotamos em nossas comunidades de fé. Trata-se da busca necessária por relacionar intimamente cristologia e pneumatologia, num movimento a partir do Espírito, que reconfigure o falar e o fazer teológico a dimensões sempre mais próximas ao Espírito de Deus.

\footnotetext{
${ }^{1}$ Cf. HILBERATH, Bernd Jochen, Pneumatologia in SCHNEIDER, Theodor (org.), Manual de dogmática, volume I, $3^{\text {a }}$ ed. Petrópolis: Vozes, 2008, p. 405-407.
} 
E aqui cabem as perguntas, por vezes desconcertantes: como discernir o Espírito? Como identificar seu sopro? Como ouvir sua voz e o que Ele diz às igrejas?

São perguntas e reflexões necessárias. Primeiro, porque fazê-las implica em restituir à teologia sua dimensão mistagógica, de encontro com o Mistério característico de toda experiência mística. A impossibilidade da linguagem em apresentar Deus - como que engaiolado porque definido/confinado - não é mera questão lingüística. Os escritos místicos traduzem esta realidade. Vemos isso, por exemplo, na(s) tentativa(s) de Santa Tereza descrever a sua experiência de Deus: as palavras lhe escapam, não porque a sua experiência se deu com algo abstrato demais para ser descrito, mas sim porque foi uma experiência com algo tão real que as palavras tornam-se insuficientes. Toda imagem de Deus é, por isso mesmo, apenas um símbolo. Todas as falas humanas sobre Deus fracassam em defini-lo. Contudo, tal fracasso expõe não a impossibilidade de se ter relacionamento com Deus, mas sim que esse relacionamento ocorre no silêncio humano. Silêncio que escuta a voz do Espírito, que permanece silencioso em meio às palavras de Deus, e que demonstra, de forma mais clara que infinitas palavras, o amor e a misericórdia do Salvador que se revela a nós.

Em segundo lugar, fazer tais perguntas é importante porque implica em integrar à espiritualidade a prática teológica, inclusive a acadêmica. Isto é, ouvir o que o Espírito diz às igrejas é o caminho para a elaboração de uma teologia mais espiritual e de uma espiritualidade mais teológica, é o caminho para reaproximar teologia e espiritualidade numa relação frutífera e vivificadora, enfim, para perceber a Bíblia como texto vivo que é gerador de uma teologia igualmente viva.

Por isso, precisamos refletir sobre um modelo de seguimento de Cristo que vincule, dialogicamente, a experiência pneumatológica vivenciada pelo próprio Jesus em sua vida e ministério com a experiência mística cristã. Em todo esse processo, ouvir a voz do Espírito é o elo de ligação entre a experiência de Jesus e a nossa enquanto homens e mulheres que param para escutar "aquilo que o Espírito diz às igrejas.".

Como caminho para a elaboração de uma resposta, é necessário ter como horizonte uma questão, especialmente desenvolvida por Yves Congar, a saber: qualquer reflexão sobre este tema precisa se guiar por uma cristologia pneumatológica e por uma pneumatologia cristológica. Manter essa relação entre Jesus Cristo e Seu Espírito se traduz em implicações significativas. Percebemos, com clareza, que não pode haver qualquer separação entre 
a cristologia e a pneumatologia: o Espírito é o Espírito de Jesus Cristo, encarnado, morto e ressuscitado pelo poder deste mesmo Espírito. Como afirma Congar, "só chegamos ao Pai pelo Filho no Espírito!"2. A pneumatologia de Congar é trinitária: "Jesus revela o Pai e o Espírito recorda nos cristãos o que

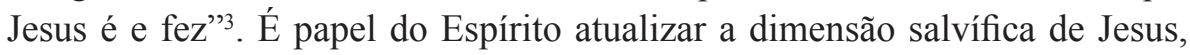
presentificando a revelação de Deus para a sua igreja de todos os tempos. Atuação esta por vezes encarada como desconcertante pela igreja. Porque, se por um lado o Espírito "não traz um ensinamento novo, mas presentifica o ensinamento de Jesus", outro a revelação que o Espírito traz não é um pacote fechado de doutrinas, mas sim dinamismo constante que guarda a fidelidade à mensagem do Filho ao mesmo tempo em que está aberto à dimensão da história. Em outros termos, a revelação do Espírito é vida, como sopro de Deus que dinamiza e orienta a caminhada cristã. Assim, o Espírito não revela coisas novas, mas atualiza a revelação. Nas palavras de Johan Konings,

A verdade na qual o Espírito da Verdade nos conduz não é coisa feita e acabada, mas a compreensão certa de cada novo momento. Ele nos guia na plenificação da verdade, porque Jesus viveu em um determinado momento, mas o Espírito que ele envia é para todos os momentos. E ele nos conduz pelo caminho da verdade plena - o caminho de Deus - não por conta própria, mas porque ele é um com Jesus e o Pai. ${ }^{5}$

Nesta compreensão pneumatológica reside um critério essencial para ouvir e discernir a atuação do Espírito em nossas comunidades de fé e em nossas vidas: "o Espírito que se manifesta nas comunidades com tanta força e tanta variedade não é outro a não ser o Espírito de Jesus." ${ }^{\text {. }}$ Em toda nossa argumentação, manteremos esse critério como bússola para o desenvolvi-

\footnotetext{
${ }^{2}$ MORAES, Eva Aparecida Rezende de, A experiência do Espírito Santo vivida pelo Concílio Vaticano II e por Yves Congar. Em: TEPEDINO, Ana Maria (org.), Amor e discernimento: experiência e razão no horizonte pneumatológico das Igrejas, São Paulo: Paulinas, 2007, p. 200-201. ${ }^{3}$ Idem.

${ }^{4}$ HILBERATH, Pneumatologia. Em: SCHNEIDER, Theodor (org.), Manual de dogmática, volume I, p. 439

${ }^{5}$ KONINGS, Johan, Evangelho segundo João: amor e fidelidade, Petrópolis: Vozes, 2000, p. 342. ${ }^{6}$ MESTERS, Carlos, Descobrir e discernir o rumo do Espírito. Uma reflexão a partir da Bíblia. Em: TEPEDINO, Ana Maria (org.), Amor e discernimento: experiência e razão no horizonte pneumatológico das Igrejas, p. 41.
} 
mento de uma proposta de espiritualidade que seja, ao mesmo tempo, mística e humanizadora.

\section{Por uma cristologia pneumatológica: como seguir a Jesus?}

Os evangelhos revelam que toda a vida de Jesus foi permeada pelo Espírito Santo. Jesus foi concebido do Espírito (Mt 1,20); ainda como recémnascido, sua identidade como Messias é autenticada pela revelação do Espírito (Lc 2,26); identidade essa publicamente afirmada pelo Pai na ocasião de seu batismo, quando o "Espírito Santo desceu sobre ele em forma corpórea como pomba" (Lc 3,22); é o Espírito quem conduz Jesus ao deserto para enfrentar sua tentação (Lc 4,1); e é o Espírito o conteúdo principal de sua primeira pregação pública, segundo o evangelho lucano (Lc 4,18-19), que serve, inclusive, como programa de seu ministério.

A presença permanente do Espírito em Jesus é o verdadeiro começo do reino de Deus e da nova criação na História. Por isso Jesus expulsa os demônios nesse poder, cura os doentes e restabelece a criação destruída. (...) Especialmente nos primeiros capítulos dos evangelhos sinóticos, o Espírito é apresentado como o sujeito divino do caminho de Jesus. O Espírito de Deus que habita em Jesus possibilita e abre a relação do Pai com o Filho e do Filho com o Pai. No Espírito Deus experimenta Jesus como o filho divino, e Jesus experimenta a Deus como o 'Abba.?

Estas afirmações evangélicas são reforçadas pelo testemunho dos apóstolos e das primeiras comunidades cristãs. O apóstolo Paulo, por exemplo, afirma que Jesus foi ressuscitado pelo poder vivificador do Espírito ( $R m$ 1,4.8,11), o mesmo Espírito que habita em nós, testificando que somos filhos de Deus e nos capacitando a chamá-lo de 'Abba (seguindo a prática de Jesus), e que derrama sobre a vida de todo cristão o amor do Pai (Rm 5,5.8,1516). Por essa razão, como diz Paulo, o Espírito é o Espírito de Cristo (Rm 8,9) e ninguém pode chamar Jesus de Senhor se não for por esse mesmo Espírito ( $1^{a}$ Co 12,3). A experiência e a vida da comunidade cristã primitiva foram edificadas em torno da certeza de que "Deus ungiu a Jesus de Nazaré com o Espírito Santo e com poder." (At 10,38), e “o mesmo Espírito em cujo poder

\footnotetext{
${ }^{7}$ MOLTMANN, Jürgen, O caminho de Jesus Cristo: cristologia em dimensões messiânicas, São Paulo: Academia Cristã, 2009, p. 151.
} 
Jesus foi à Galiléia também impulsiona as discípulas para a missão. O Espírito torna-se o catalizador, a força orientadora e motriz da missão."

O Espírito de Deus estava sobre Jesus. Isto constitui muito mais que uma afirmação teológica; é o cerne mesmo da missão do próprio Jesus e, conseqüentemente, de sua igreja. Ambas são pneumatológicas. A fala de Jesus - "Eu vos envio assim como o Pai me enviou" - se faz acompanhar do sopro do seu Espírito sobre seus discípulos e discípulas (cf. Jo 20,21-22). Assim, é o Espírito de Jesus quem autentica nossa missão cristã e quem fornece os critérios para a realização da mesma. Em outras palavras, o Espírito que possibilitou a encarnação no ventre de Maria também possibilita nossa encarnação no mundo.

Esta compreensão - uma cristologia pneumatológica - constitui uma chave hermenêutica para a elaboração de uma espiritualidade genuinamente cristã. Somos chamados a encarnar na vida, assim como Jesus o fez. Nesse caminho, recebemos do Espírito de Jesus a graça, a coragem, a sabedoria, o amor e a autenticação de nossas obras que, por serem obras que o Espírito realiza por nosso intermédio, glorificam a Jesus. Por essa razão, a igreja cristã deve ser fundamentalmente pneumatológica, pois é o Espírito que permite a sua existência em novos momentos históricos, atualizando a mensagem de Jesus sem que esta seja engessada ou aprisionada em fórmulas literalistas e fundamentalistas geradoras de peso e morte. O Espírito é guia a toda a verdade, porque fala sobre o que recebe do Filho e, por isso, o glorifica (cf. Jo 16,12-15). Por isso, toda proposta cristã que se coloca sob a ação deste Espírito também, como conseqüência, glorificará a Jesus e transmitirá sua verdade ao mundo. Verdade que é sempre vivenciada em amor, perdão, alegria e paz (cf. Jo 20,20-23).

O Espírito fornece base e substância à nossa pregação, pois confirma o amor de Deus para conosco, amor esse que nos posiciona voltados para o nosso próximo. Dessa forma, podemos definir o lugar da igreja no mundo: a igreja encontra-se no outro, especialmente, no outro necessitado e oprimido, a quem estendemos pão, água e vestes. E ao fazer isso, a igreja encontra a Cristo e a seu Espírito. A espiritualidade que surge desse encontro é, antes de mais nada, relacional; espiritualidade que busca encontrar-se com o outro pois é capaz de enxergar neste um alvo do convite do Pai ao banquete em seu reino.

Dessa forma, as relações neste reino de Deus pregado por Jesus são fraternas. Enxerga-se o outro. Ouve-se sua voz. Assim, pela força do Espírito de Jesus, redescobre-se a caridade como centro da vida diante de Deus e

\footnotetext{
${ }^{8}$ BOSCH, David J. Missão transformadora: mudanças de paradigma na teologia da missão, São Leopoldo: Sinodal, 2002, p. 147.
} 
diante do próximo. A fé que daí surge é, primeiramente, fé voltada para fora, expressa num ato de saída de si mesmo, caracterizando-se por ser um compromisso com Deus e com o próximo, em especial o necessitado, o oprimido, o cansado, o sobrecarregado, o culpado etc.. "Em tal perspectiva", declara Gustavo Gutiérrez, "a inteligência da fé aparece não como inteligência da mera afirmação - e quase recitação - de verdades, porém de um compromisso, de uma atitude global, de uma posição diante da vida" . Surge dessa compreensão uma definição de igreja, reafirmada pelo Concílio Vaticano II: uma "igreja de serviço e não de poder, que não está centrada em si mesma e que só se 'encontra' quando 'se perde', quando vive as alegrias e esperanças, as tristezas e angústias dos homens de nosso tempo." 10

Pleno da experiência do Espírito de Deus, Jesus Cristo é o caminho que vincula em si mesmo a verdade e a vida do Pai (cf. Jo 14,6). Este caminho passa pela encarnação, pelo fato de que a Palavra se fez carne, suor e lágrimas. Assim, na encarnação se realiza o modo de ser de Deus entre nós: Jesus é o revelador de Deus para os seres humanos. Quem vê a Jesus, também encontra o Pai. Olhar para Jesus, portanto, é perceber como Deus é, age, sente, chora, se alegra, compartilha alegria do reino e sofre junto as dores do sofrimento humano. Como diz José $\mathrm{M}^{\mathrm{a}}$ Castillo, "não se conhece a Deus elevando-se acima do humano ou fugindo da humanidade, mas procedendo exatamente no sentido contrário. Deus é conhecido e encontrado no que é próprio do ser humano" 11 . Nesse sentido, tudo o que ajuda homens e mulheres a serem humanos - isto é, todo processo de humanização do ser - provém de Deus e constitui sua vontade.

Por isso, podemos afirmar que seguir a Jesus é muito mais do que seguir um corpo de doutrinas ou um conjunto de rituais e liturgias repetidas à exaustão em nossos encontros dominicais. Seguir a Jesus é tomar a forma de Jesus na vida. Isso só pode se dar quando ocorre uma identificação com seus projetos, com sua maneira de ser e de viver. É encarnar, na nossa vida, o reino de Deus e sua ética. Enfim, seguir ao Jesus pleno do Espírito significa adotar os seus projetos para a vida, que não são projetos de poder nem de dominação, mas sim de serviço. O seguimento de Jesus requer de nós que façamos as mesmas opções por pessoas e lugares que Jesus fez. Isso não significa sair do mundo. Pelo contrário, significa entrar no mundo integralmente, pois é o mundo o

\footnotetext{
${ }^{9}$ GUTIÉRREZ, Gustavo, Teologia da Libertação: perspectivas, $5^{\mathrm{a}}$ ed. Petrópolis: Vozes, 1985, p.19.

${ }^{10}$ GUTIÉRREZ, Teologia, p. 20.

${ }^{11}$ CASTILLO, José Ma , Deus e nossa felicidade, São Paulo: Loyola, 2006, p. 29.
} 
nosso lugar da missão. Movidos pelo Espírito de Jesus, somos chamados a encarnar no mundo, assim como ocorreu com o próprio Jesus, redescobrindo, no ambiente da nossa prática cristã, a vivência com o nosso próximo, com o outro. Seguir a Jesus é manter uma atitude relacional, não hierárquica, com o próximo. De fato, a espiritualidade que surge de Jesus motiva relacionamentos baseados não no poder ou na força, mas na fraqueza. A kênosis do Filho torna-se também a nossa, pela capacitação do mesmo Espírito que esteve sobre Jesus. Por isso, não existe espaço para hierarquia no reino de Deus! Isso porque no reino de Deus todos e todas são convidados à mesma mesa do Pai, ao seu banquete, e à experiência com sua graça e amor.

\section{Por uma pneumatologia cristológica: como ouvir a voz do Espírito?}

O Espírito de Cristo se faz ouvir no mundo. O Espírito fala. Mas o que significa ouvir a sua voz? E qual espiritualidade que nasce dessa escuta?

Antes de tudo, ouvir o Espírito implica em recolher, do cotidiano da vida, imagens capazes de nos sensibilizar à voz de Deus. Toda a criação é resignificada como espaço litúrgico da atuação do Espírito de Deus. E era isto o que Jesus fazia: para ele, os pássaros no céu falam do cuidado do Pai sobre aqueles que valem mais que passarinhos; as flores no campo de igual forma revelam a bondade e providência de Deus (cf. Mt 6,26-34). Até mesmo nas menores sementes, Jesus enxergava símbolos do reino de Deus que, aos poucos, crescia até tornar-se árvore capaz de abrigar passarinhos em seus galhos: sinais claros da acolhida que o reino de Deus proporcionava às pessoas. Jesus soube ouvir a criação como voz sempre presente do Pai e, por isso, Ele vivia sua vida em gratidão. Dessa forma, ouvir a voz do Espírito significa reconhecê-lo no cotidiano da vida: no "falar, rezar, caminhar, viajar, orientar, cantar, criticar, decidir, ficar alegre, crescer, anunciar, servir etc." ${ }^{12}$. A espiritualidade que surge daí é vivenciada no amor que o Espírito faz germinar entre seres humanos. Afinal, somente o amor valida o seguimento de Cristo (cf. Jo 13.34-35).

Ouvir a voz do Espírito e sentir seu vento no rosto implica em humanizar-se na relação com Deus. O Espírito de Jesus não nos faz perder nossa humanidade; não nos torna anjos. Isso tem uma direta conseqüência em nossa relação comunitária: não podemos ser além do que somos. Porque se nós

\footnotetext{
${ }^{12}$ MESTERS, Carlos, Descobrir e discernir o rumo do Espírito. Uma reflexão a partir da Bíblia. In: TEPEDINO, Ana Maria (org.), Amor e discernimento: experiência e razão no horizonte pneumatológico das Igrejas, p. 26-27.
} 
aparentamos ser algo que não somos, nós nos desumanizamos. Nas palavras de Fernando Pessoa, nossa vocação é ser íntegro:

Para ser grande, sê inteiro

Nada teu exagera ou exclui

Sê todo em cada coisa

Põe quanto és no mínimo que fazes

Assim em cada lago a lua toda

Brilha, porque alta vive. ${ }^{13}$

Ouvir a voz do Espírito também implica em humanizar o outro. Em outros termos, o Espírito nos impulsiona a devolver a humanidade aos homens e mulheres, considerados meros objetos pela ótica moderna, "coisas" que podem ser usadas para satisfazer desejos espúrios de lucro e dominação. O Espírito nos devolve a dignidade de sermos chamados filhos e filhas de Deus e de chamarmos o Senhor de Aba (Rm 8,15-16); o Espírito nos devolve a permissão para o sentir, para gemermos com Ele em nossas fraquezas, pois não sabemos como orar, mas Ele intercede a nosso favor (Rm 8.26-27); é o Espírito, enfim, que nos garante a esperança da redenção e da reconciliação de toda a criação com o Pai, pois nos torna participantes de sua vida e graça. Pelo Espírito, experimentamos o amor de Deus que foi derramado em nossos corações (Rm 5,5). Isto, obviamente, produz conseqüências na relação com nosso próximo. Tornamo-nos capazes de chorar com os que choram, de dar suporte ao outro em amor. Fazemos de nossos encontros litúrgicos espaços para troca de vida, para conversa franca, para perdão mútuo, para ver na face de nosso irmão ou irmã o rosto de Jesus e, assim, servi-lo(a) em caridade. "Levai as cargas uns dos outros", diz Paulo, "e assim cumprireis a Lei de Cristo" (Gl 6,2), que é a mesma lei do Espírito da vida, que nos livrou da lei do pecado e da morte $(\mathrm{Rm} 8,2)$.

\section{Conclusão: Aquele que tem ouvidos, ouça. Nós ouvimos, Senhor!}

A voz do Espírito quer ser ouvida por nós. Nosso ativismo eclesiástico, que muitas vezes disfarça uma fuga de Deus e de nós mesmos, precisa dar lugar a uma atitude de quietude, de pausa para reflexão e escuta. O Espírito fala. Conseguimos ouvir sua voz? Estamos atentos ao seu clamor? Só culti-

\footnotetext{
${ }^{13}<$ www.luso-poemas.net/modules/news/article.php?storyid=77923> . Acessado dia 25/11/2012 às $23: 34 \mathrm{~h}$.
} 
varemos uma espiritualidade genuinamente cristã se pararmos para ouvir sua voz e, ao fazer isso, encarnarmos na nossa vida o sopro sempre renovador do Espírito de Jesus.

A experiência do Espírito de Deus leva o cristão a voltar-se para tudo e todos, agora a partir de e com Deus, para então se reconciliar com a criação. Isso reflete um pensamento paulino muito claro, a saber, que "Deus estava em Cristo reconciliando consigo mesmo o mundo" e "nos confiou a palavra da reconciliação" (II Co 5,19). Toda a criação é, em Cristo, reconciliada; portanto, não pode haver espaços para dualismos, mesmo em nome da experiência com o Espírito Santo. A partir disso, pode-se chegar a uma conclusão: a espiritualidade cristã não é vivenciada fora do mundo, antes é encarnacional, e isto considerado até a última conseqüência. Somos mais espirituais à medida em que somos mais humanos, vinculados ao próximo; "a verdadeira eternidade vive no plano do relacionamento pessoal"14.

Ouvir a voz do Espírito, enfim, é abrir-se para seu soprar, sempre novo e freqüentemente imprevisível. O Espírito sopra onde quer, e não sabemos de onde vem ou para onde vai. Apenas sabemos que, em Jesus, tornamo-nos nascedouro do seu Espírito: nascemos nele e ele nasce e vive em nós. E assim, seguimos a Jesus.

\section{Referências bibliográficas}

BOFF, Leonardo \& BOFF, Clodovis. Como fazer Teologia da Libertação. Petrópolis: Vozes, 1986.

BOSCH, David J. Missão transformadora: mudanças de paradigma na teologia da missão. São Leopoldo: Sinodal, 2002.

CASTILLO, José Ma . Deus e nossa felicidade. São Paulo: Loyola, 2006.

CONGAR, Yves. Revelação e experiência do Espírito. São Paulo: Paulinas, 2005.

GUTIÉRREZ, Gustavo. Teologia da Libertação: perspectivas. $5^{\mathrm{a}}$ ed. Petrópolis: Vozes, 1985.

KONINGS, Johan. Evangelho segundo João: amor e fidelidade. Petrópolis: Vozes, 2000.

\footnotetext{
${ }^{14}$ MOLTMANN, Jürgen, O Espírito da vida: uma pneumatologia integral, Petrópolis: Vozes,
} 2010, p. 30. 
MOLTMANN, Jürgen. O Espírito da vida: uma pneumatologia integral. Petrópolis: Vozes, 2010.

MOLTMANN, Jürgen. O caminho de Jesus Cristo: cristologia em dimensões messiânicas. São Paulo: Academia Cristã, 2009.

ROCHA, Alessandro. Espírito Santo: aspectos de uma pneumatologia solidária à condição humana. São Paulo: Vida, 2008.

SCHNEIDER, Theodor (org.). Manual de dogmática: volume I. $3^{\mathrm{a}}$ ed. Petrópolis: Vozes, 2008.

SCHILLEBEECKX, Edward. História humana: revelação de Deus. São Paulo: Paulus, 1994.

TEPEDINO, Ana Maria (org.). Amor e discernimento: experiência e razão no horizonte pneumatológico das Igrejas. São Paulo: Paulinas, 2007.

TEPEDINO, Ana Maria \& ROCHA, Alessandro (orgs.). A teia do conhecimento: fé, ciência e transdisciplinaridade. São Paulo: Paulinas, 2009.

Sites:

$<$ www.luso-poemas.net/modules/news/article.php?storyid=77923>. Acessado dia 25/11/2012 às 23:34h.

Marcio Simão de Vasconcellos Mestre em Teologia Sistemático-Pastoral na PUC-RJ Rio de Janeiro/RJ - Brasil E-mail: marciosvasc@gmail.com

Recebido em: 01/06/13 Aprovado em: 07/08/14 